University of Nebraska - Lincoln DigitalCommons@University of Nebraska - Lincoln

2004

\title{
Artifact, Landscape, and Temporality in Eastern Mediterranean Archaeological Landscape Studies
}

LuAnn Wandsnider

University of Nebraska-Lincoln, lwandsnider1@unl.edu

Follow this and additional works at: http://digitalcommons.unl.edu/anthropologyfacpub

Part of the Archaeological Anthropology Commons

Wandsnider, LuAnn, "Artifact, Landscape, and Temporality in Eastern Mediterranean Archaeological Landscape Studies" (2004).

Anthropology Faculty Publications. 84.

http://digitalcommons.unl.edu/anthropologyfacpub/84

This Article is brought to you for free and open access by the Anthropology, Department of at DigitalCommons@University of Nebraska - Lincoln. It has been accepted for inclusion in Anthropology Faculty Publications by an authorized administrator of DigitalCommons@University of Nebraska Lincoln. 


\title{
Mediterranean Archaeological Landscapes: Current Issues
}

\author{
Edited by
}

Effie F. Athanassopoulos and LuAnn Wandsnider

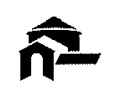

UNIVERSITY OF PENNSYLVANIA MUSEUM OF ARCHAEOLOGY AND ANTHROPOLOGY PHILADELPHIA 
Copyright (C) 2004

University of Pennsylvania Museum of Archaeology and Anthropology 3260 South Street Philadelphia, PA 19104-6324

First Edition

All Rights Reserved

\section{Library of Congress Cataloging-in-Publication Data}

Mediterranean archaeological landscapes : current issues / edited by Effie F. Athanassopoulos and LuAnn Wandsnider. - 1st ed. p. cm.

Includes bibliographical references and index.

ISBN 1-931707-73-1 (hardcover : alk. paper)

1. Mediterranean Region-Antiquities. 2. Excavations (ArchaeologyMediterranean Region. I. Athanassopoulos, Effie-Fotini. II. Wandsnider, LuAnn.

DE60.M417 2004

930'.09822--dc22

2004008734

Printed in the United States of America on acid-free paper. 


\title{
Artifact, Landscape, and Temporality in Eastern Mediterranean Archaeological Landscape Studies
}

\author{
LuAnn Wandsnider
}

$\mathrm{I}_{\mathrm{s}}^{\mathrm{n}}$ ntensive survey over the last several decades has detailed an archaeological surface record in the Mediterranean that Cherry (1983:395, emphasis in original) describes as "likely to consist of a virtually continuous spatial distribution of material over the landscape, but a distribution extremely variable in density." In addition, geoarchaeological work, often coupled with survey, has demonstrated just how dynamic Mediterranean surfaces have been. Both of these field practices, intensive survey and geoarchaeology, were carried out in part to enable regional settlement pattern studies, to collect accurate, reliable, and precise data about past settlements and their location with respect to each other and with respect to aspects of the landscape (Cherry and Shennan 1978).

As a result of intensive surface survey and geoarchaeological work, a paradox has become apparent. This paradox is that the surface archaeological record is of such a quality that the settlement mode of interpretation, the impetus for the high quality work undertaken in the Mediterranean, may be inappropriate. That is, it demonstrates that rather than a record of settlements awaiting discovery and definition by the archaeologist, the archaeological record is better considered a record of places with different material histories, both cultural and natural. Viewed in this way, the surface record, currently interpreted in terms of settlements and using empirical, historical conventions, instead becomes a source of information on the human condition at a variety of spatial and temporal scales.

Below, I make the case for this paradoxical situation (see also Holdaway and Wandsnider n.d.; Wandsnider 2004; Wandsnider and Holdaway n.d.). Archaeologists working elsewhere and not explicitly concerned with the archaeological landscape have come to a similar realization, concluding that a metaphysical shift in the approach to archaeological deposits appears warranted. Given this shift, how should interpretation of Mediterranean archaeological landscapes proceed? Two additions to the archaeological tool kit are suggested: a library of potential multi-temporal processes and a series of three interpretative tools. 


\section{A Paradox in Mediterranean Archaeological Landscape Studies}

Over the last several decades, the Mediterranean surface record primarily has been studied using the interpretative vehicle of regional settlement patterns (Barker et al. 1999; Kardulias 1994a; Keller and Rupp 1983). Systematic surface survey is the main tool used to collect data on the location and type of past settlement. Settlement type is determined using common sense and correlational dating based on ceramics establishes the time period or periods of occupation (Binford 1992). The questions driving such studies have been mostly implicit rather than explicit (Jacobsen 2000; Morris 1994), embedded in a tradition of scientific humanism, wherein the "universal man," as he interacts with his environment, is the object of scrutiny (Fotiadis 1995). Observed settlement patterns have been interpreted empirically and rely on an historical concept of agent, time, and causation wherein settlement patterns are taken to reflect culture history, rendered with increasing sophistication (Jacobsen 2000:5).

As discussed in the introductory chapter, regional settlement pattern studies have been avidly pursued throughout the world, no less so than in the Mediterranean. But, the surface archaeological record and the tool of systematic surface survey, used to find and document sites (usually inferred to represent settlements of some sort), were, in the Mediterranean, explicitly recognized as problematic. In a seminal paper on archaeological survey in the Mediterranean, Cherry (1983:379) summarized the recognized intractabilities of survey data employed in settlement pattern studies:

a. The necessarily coarse chronological framework, seldom more precise than a century and often much vaguer than that, which results from the use of aggregate collections of poorly preserved surface material, so that

b. maps of site distributions based on survey data to some degree (often unknown) must be taken to represent "palimpsests" of sites, not all of which were necessarily in use simultaneously...

c. The smearing and blending of surface finds, whether by natural or human agencies, means that small sites may often go unrecognized and sites of all sizes and types may be difficult to define accurately in spatial terms.

d. Information about the internal organization and function of sites is usually very difficult to obtain.

These limitations of the surface archaeological record and the survey product were cited by Hope Simpson (1983) as an indictment of stand-alone survey as a method for discovering and reporting on past settlements and of the conduct of intensive regional settlement studies. Cherry (1983), in response, offered a number of prescriptive measures to ensure and understand data consistency and quality, including an emphasis on intensive survey and methodological refinements. Many 
of these measures were adopted by Mediterranean practitioners in the "New Wave" (Cherry 1994) of regional studies. For example, Gallant (1986) offers a method for reliably defining sites relative to regional sherd density (see also Cherry et al. 1991; Given et al. 1999). Numerous surveys (e.g., Barker 1995b; Bintliff et al. 1999; Given et al. 1999; Van Andel and Runnels 1987) are concerned with the degree to which evidence for sediments are buried or eroded away, leading to an incomplete picture of settlement. $l t$ is in part this latter concern, along with that of paleoenvironmental reconstruction, that led to the incorporation of a geomorphologic specialist on the field team.

Reflecting on the state of the discipline in 1994, Cherry noted encouraging signs in that previously ignored cultural remains were now receiving the attention that Prehistoric and Classic rural domestic landscapes had earlier received. Thus, ritual activities, urban centers, and the Late Antique were now also being approached using intensive survey.

But, he (Cherry 1994:103-105) also identified several continuing problems. That is, progress had been made in finding sites, but classification of sites according to functional type using surface materials was proving difficult. Targeted excavation and geophysical work were suggested as possible remedies. Also, archaeologists had documented numerous "off-site" artifact scatters, but the treatment, reporting, and interpretation of those off-site scatters he found to be widely divergent. Cherry (1994:104-105) noted that "surprisingly little progress has been made toward a consensus about the taphonomic processes that produce such distributions, or toward an understanding of why in some regions artifacts are to be found everywhere, while in others they are relatively rare outside of 'sites'."

Mediterranean archaeologists continue to soldier on using the regional settlement vehicle of interpretation, but acknowledging the difficulties of their database in doing so. For example, Cherry and colleagues (1991:34) and Given and colleagues (1999:23) explicitly acknowledge that in designating "sites" from deposits with complex formational histories and in moving from "sites" to "settlements," they are engaging in interpretation, in the conscious construction of analytic units using explicitly detailed criteria.

Other regional studies have taken one further step. Having identified sites through survey and interpreted them as settlements, Bintliff (1999b) and Sbonias (1999a; 1999b) go on to identify another series of problems that attend the use of archaeological settlement data to address issues of regional demography. They offer a series of conventions to be used to surmount these "methodological hindrances" (Binfliff 1999b:21) and recognize that their demographic estimates must be considered provisional.

The paradox is that through the application of technically sophisticated intensive survey and attention to geological surface processes, the problems they were intended to solve-the spatial definition of sites, of chronological assignment, and of functional interpretation-have not disappeared. Indeed, sophisti- 
cated survey work sometimes coupled with targeted excavation in the general eastern Mediterranean (e.g., Barker 1995a; 1995b; Cherry et al. 1991; Given et al. 1999; Van Andel and Runnels 1987) throws into sharp relief the stubborn nature of these difficulties.

John Chapman explicitly discusses these difficulties. For example, when relatively higher sherd densities are observed at a site, does this indicate more intensive deposition, a higher site population or nucleation, or a longer occupation span (Chapman 1999:69)? And multiple sites, dated with coarsely resolved ceramics, are often treated as contemporaneous enough to permit settlement reconstruction, when in fact they may not be. Indeed, in at least two cases, high-resolution radiocarbon dating of associated buried sediments revealed the complex formation histories of surface palimpsest deposits (Chapman 1999; Whitelaw 2001), emphasizing that "contemporaneity" is very much dependent on the resolution of the measuring device, in this case, ceramics; the degree of contemporaneity amongst and between archaeological deposits may not allow for the valid reconstruction of entities like settlement systems.

These observations as well as the fact that surface archaeological deposits are still considered problematic even after the application of sophisticated technologies and methods for finding, parsing, and interpreting sites and settlements suggests that perhaps the problem lies not with the surface archaeological deposits but with the vehicle used to interpret those deposits. Below, I suggest abandoning the regional settlement studies vehicle and embracing the complex formational nature of archaeological landscape deposits.

\section{Time in Archaeological Landscape Studies}

The abiding technical issues alone are enough to challenge the regional settlement pattern studies vehicle, but another challenge comes from the ontological domain. Here, the empirical, historical, reconstructive mode of interpretation commonly utilized to interpret the formationally complex landscape is threatened.

The issue again ties back to the palimpsest (Cherry 1983; above) nature of the archaeological landscape. As Binford (1981b) emphasized in his discussion of the Pompeii premise, the archaeological record is qualitatively different from the materials and behaviors observed during quick-time ethnographic study (see also Foley 1981a; 1981b). It is denser than that documented during short-span ethnoarchaeological observation. This being the case, Binford and Foley argue that such apparently temporally thick deposits are owed to deposition over generations and, thus, are ideal for studying longer-term organization and structure, rather than short-term behavioral events (see also Clark 1994).

Over the last decade, these powerful observations have been rendered more nuanced. Rather than being taken as only referable to longer-term phenomena, archaeologists are exploring the potential of archaeological deposits for informing on a variety of processes operating at a variety of tempos, from short (behavioral), 
to medium term (ecological, demographic), to longer term (geologic, tradition, or mentalité). "Time perspectivism" is the label applied to this pursuit (Bailey 1987; Knapp 1992a; Murray 1999) and two expressions of it are evident. Bailey (1983; 1987), Butzer (1982), and Dewar and McBride (1992) independently offer various hierarchical temporal schemes derived from biological or ecological domains. Drawing from history, Barker (1995b), Bintliff (1991a; 1999a), and contributors to Knapp (1992b) recruit Braudel's schema of événementsconjoncture-longue durée (see Athanassopoulos, this volume) as another way to organize temporal interpretations.

Attempts at multi-temporal interpretation to date have produced tantalizing results. For example, the account for Boeotia from $600 \mathrm{BC}$ to $\mathrm{AD} 700$ (Bintliff 1991a) presents different data classes (texts, regional site distributions, erosional sequences) and recogniżes that they are sensitive to processes with different temporalities. The intersection of processes with different temporalities is not considered, however. Similarly, multi-scalar temporal processes are discussed generally for the Biferno valley, with important geographic differences emphasized (Barker 1995b). While the spatial scale of analysis changes through time, hierarchical explanation, i.e., a consideration of the interplay between processes operating at different tempos, is not attempted. In part, the difficult task is how to present history at multiple temporal and spatial scales.

While anti-historicist in orientation, but not explicitly embracing time perspectivism, Olivier's (1999) analysis of the Iron Age "Princely" grave at Hochdorf provides a useful model. Here Olivier focuses on three different classes of archaeological material (artifacts, the interred person, and the funerary monument) and recognizes general processes operating at different tempos. The first concerns the life cycle of objects deposited in the grave, their manufacture, use, and burial, and operates over a few years to a few decades. The second concerns the recognition of the status of the deceased, from death to burial, and operates over the span of a few days to a few weeks. Finally, the relationship of the living with the dead person, extending from the erection of the funerary monument to later re-occupation or rearrangements, lasts over generations and perhaps for centuries.

The important point is that Olivier creates and uses interpretative units that draw on the strength of the archaeological materials but also are sensitive to the processes under study. Other multi-temporal interpretations rely too fundamentally, 1 suggest, on interpretative units that are quasi-ethnographic entities, i.e., occupations, sites, and settlements. In light of our formational understanding of archaeological materials, Smith's (1992:29-30) observation is germane: we study not Mayan "house floors" but rather Mayan "house floor series." Similarly, our sites are not settlements; rather, they may be settlement series. As he also notes, exactly how to interpret a house floor series and, by extension, a settlement series, remains underexplored.

Consideration of a multi-temporal model of agent, time, and causation is nonetheless especially important for Mediterranean archaeological landscape 
studies because it forces archaeologists to abandon the ready empirical, historical interpretive crutch (Clark 1994; Olivier 1999). That is, it opens the doors to supra- (e.g., the Annales mentalités) and sub-historical (e.g., mortuary practices) processes, which will require theoretical and methodological attention in order to be studied archaeologically (see Hill, this volume). It also emphasizes the likelihood of complex processual linkages (McGlade 1995), for example, between deforestation and political cycles, as well as hierarchies of causation (Bailey 1983).

\section{A Metaphysical Shift}

In the preceding, I have described the paradox that exists between our current formational understanding of the archaeological landscape and how it is documented, in terms of units that are functional, synchronic, and quasi-ethnographic entities. Equally frustrating, by approaching the archaeological landscape using the settlement pattern vehicle, archaeologists are locked into interpretive schemes that are historic or ethnographic in nature. Other interpretative temporalities are difficult to consider.

All of this argues for a metaphysical shift in how archaeological landscapes are conceptualized and approached along at least three related dimensions. The first is from a focus on people and individual activities to that of places or landscapes (Binford 1982; Smith 1992). Most archaeological settlement pattern survey is predicated on the notion of recovering or reconstructing common sense, ethnographic entities like settlements. Such entities make sense in the lived lives of humans. But, the material artifactual and landscape constructions of humans have lives very different from their creators. It is these materials, especially the landscape, that become the focus. As a result of place use with different intensities and deliberations, a cultural landscape of places was (and is constantly) constructed (Tilley 1994). To see place in space, to map the relief of the cultural landscape, we cannot only focus on sites and settlements: a landscape perspective is necessary.

Related to the above is Dunnell's (1992) case for a shift from a site-based approach to an artifact or feature-based approach to archaeological landscapes. Dunnell argues that each land parcel has its own formational or taphonomic history. Moreover, sites, dense concentrations of archaeological materials, are too coarse a unit with which to decompose that history. Rather, by focusing on artifacts, artifact assemblages, features (and surfaces, Sullivan 1978), the possibility of tracing out formation histories for individual (arbitrarily defined) landscape parcels exists.

A third dimension is related to the nature of material, be it artifact or landscape. We understand that materials participate in human lives in both tangible and intangible ways, that they are manipulated by people and that, in turn, people are manipulated by them. They have mass, are traversed, are differentially 
mutable, and have varying, culturally specific capacities for performing in people lives. Thus, it is too simplistic to argue that people exploit or are constrained by their environment and it is equally too simplistic to say that people create the landscape. Rather, people, artifacts, and landscapes are in a constant dialogue that some (Green 1997; McGlade 1995; 1999a) argue is unparseable. But, of course, as analysts, we can approach the artifacts and the cultural landscape however we wish, if it buys us insight.

In sum, the overall metaphysical shift is from that of a focus on quasi-ethnographic kinds (sites and settlements) to that of formational (and therefore, historical) material variation, or from so-called essentialism (Dunnell 1980; 1986; Lyman et al. 1997; Ramenofsky and Steffen 1998) to ontological materiälism (but see Binford 1992 for comment on these terms). This metaphysical shift registers in the consideration of Mediterranean archaeological landscapes: where formerly functional, ethnographic, and historic models of agent, time, and causation were embraced, today we see increasing use of multi-temporal, multi-processual modes of interpretation.

\section{Studying Mediterranean Archaeological Landscapes}

It is all very well to conceptualize surface archaeological deposits as palimpsest deposits owed to the operation of multiple processes (cultural and natural) with different temporalities. It is an altogether different task to interpret the contingent human-nature trajectories from those palimpsest deposits. To do so requires several tools, which are only partially developed. Here, I focus on two, both of them middle range (Binford 1981a) in nature. The first is concerned with developing a library of human and natural processes, the second, with taking advantage of the material histories of artifacts, features, and surfaces to interrogate landscape formational histories.

Smith (1992:25) notes that Braudel's temporal schema with its hierarchy of different sociocultural processes and constraints was empirically derived from his historical studies of the Mediterranean. McGlade (1999b; see also Knapp 1992a) suggests that such processes (along with biological and ecological processes) have their own inherent tempo. We currently have only a shadow of an understanding of human and natural processes with known ranges of temporalities, spatial ranges, and collateral processes. For the Mediterranean, such a library might contain information on the rebound rates of forests under range of different conditions, something currently under construction by landscape ecologists working there (Goldammer and Jenkins 1990; Naveh and Lieberman 1994). Palynologists working in concert with other paleoenvironmental scientists may provide the longer view of this process (Bottema 1991; Bottema and Woldring 1984).

Other processes include the dynamic and modes of colonizer-colonized relationships. For example, Elton (1996) and Wells (1999) summarizing Roman occupation 
in the provinces describe a similar pattern. Roman legions were garrisoned in newly acquired territory until rebellion was unlikely, usually a generation in length. At this time, legions were relocated to other areas. With historical data on colonizer-colonized dynamics from a series of different contexts, along with attending studies on the associated effects of different colonizer-colonized relationships, some of the dynamic we likely see archaeologically may become interpretable. Here historical documents are essential for building this body of reference knowledge (Sabloff 1986; Smith 1992) and Murray (1997) suggests other research tactics.

The process library is important not purely because we desire an archaeological signature of particular processes. Such a library is necessary before we can begin to determine the temporal or spatial scales at which archaeological observation can occur and at which the interaction between and among other processes becomes possible (Bailey 1983). For example, Rackham and Moody (1996; see also Moody 1997) argue that it is not "climate" that is responsible for Early Antiquity erosional deposits documented in eastern Mediterranean contexts but rather "weather," i.e., spatially and temporally unpredictable local rainfall events. This is a debate with many facets: on the nature of the relationship between "climate" and "weather," between precipitation events and slope failure events, and between the archaeological proxies and the systemic realm phenomenon they measure. This is a relationship that we can understand in the here and now, when populations of slopes and potential slope failures are considered (which is what regional documentation is so good at providing).

The second important addition to the interpretative tool kit includes inferential tools based in material history, the strength of archaeological deposits. Such tools depend on our understanding of the elements of archaeological depositsartifacts, assemblages, features, and surfaces - as differentially performing and differentially enduring time travelers.

Artifacts may have been designed to have relatively short use-lives (e.g., ceramic tea cups used by travelers on the Indian Rail System before the advent of paper and plastic cups) or very long use-lives (e.g., burial vessels). They may be designed to be transported over great distances (amphorae) or as furniture essentially remaining in one place (pithos). They may be designed to signal social status (as in blackwares employed in lieu of iron wares). And, their archaeological signature, i.e., sherds, is related in systematic ways with the original vessel; that is, we can identify an attending Mickey Mouse Law (Flannery 1973) with important implications: small vessels break into fewer sherds per vessel than do massive vessels, other things being equal (Fentress and Perkins 1989).

The design and then the actual use to which vessels are put determine the rate at which individual artifacts enter archaeological deposits (Ammerman and Feldman 1974; David 1972; DeBoer 1974). Thus, comparing relative frequencies of sherds from vessels with different sizes and also with different uselives may permit a closer reading of residential occupation dynamic (all other things, e.g., scavenging, visibility, being equal). That is, we expect a basal 
frequency of storage vessels and roof tile sherds. However, the frequency of sherds from short-lived vessels, with greater opportunities to be introduced into residential deposits, should be sensitive to the occupation dynamic (e.g., Varien and Mills 1997).

In contrast to that discussed below for features, the iconographic capacity of one sherd is likely low. The iconographic capacity of sherd aggregates remains to be fixed. Given (this volume) presents information that such aggregates have a monument-like iconographic capacity for contemporary Cypriot farmers.

Artifacts differentially accumulate on surfaces and in deposits because of the dynamic associated with their manufacture, use, and emplacement, loss, or discard. Features such as walls, houses, temples, and baths, on the other hand, reflect a very different dynamic. They are introduced to the landscape where, depending on construction material; they have the potential to be almost eternal. This enduring capacity means that they have the potential to serve as temporal buoys against which subsequent activities may be monitored. That is, once constructed, they offer the potential to see how such features were maintained, modified, or destroyed. For example, in Hellenistic and Roman Western Rough Cilicia (southern Turkey), we see various building trajectories, temples converted to baths, tombs converted to temples, and so forth. Presumably the directionality of the conversion is not random, but such remains to be explored.

Features may be deliberately or not imbued with great iconographic capacity. This capacity, in turn, may make them lightning rods for how subsequent occupants react to extant monuments. In a more recent context, Chapman (1994) reports on the deliberate destruction of monuments with local historical significance (see also contributors to Bradley and Williams 1998). Because of their enduring material qualities, features offer a unique means to perceive events that likely occurred outside the modal range of human behaviors (Wobst 1978), that is, very rarely and under great stress. And, feature history, documented through its construction, modification, and destruction using simple but powerful archaeological observation on sequencing (Sullivan 1992) and perhaps rendered using Harris-matrix-like (Harris 1979) sequence models (e.g., Bleed 2001), provides insight not otherwise obtainable.

Moreover, their initial construction indicates that a certain threshold has been breached. That is, the construction of a fortification wall variously signals the presence of a threat, the nature of that threat in light of extant siege craft $(\mathrm{McNi}$ coll and Milner 1997), that someone or something is to be protected, that labor and resources existed to construct that wall, and/or that a political infrastructure to organize construction exists. As Fletcher (1995) documents for the growth of cities, once constructed, the very materiality of features constrains subsequent modifications, removals, and so forth. People may well endure the inconveniences and worse of extant features because of the high cost of remodeling them to conform to current needs. At some point, however, another threshold may be breached, wherein those high costs become tolerable or necessary. 
Surfaces are similar to features in that they potentially host and remember different place histories (Sullivan 1978). They are places where artifacts and features accumulate or not. Their use-lives are dictated by geomorphological activity and perhaps also by human activities that differentially affect the quality of surfaces as work and living spaces. For example, surfaces are created and maintained as agricultural terraces are constructed. On these surfaces may accumulate the incidental artifacts associated with agriculture as well as those owed to deliberate manuring. Should the terraces no longer be maintained, the potential exists for some surfaces to become eroded and others buried as terrace walls fail. Like deliberately installed features, surfaces offer a slate on which the hand of man and nature may write.

Given these elements with differential sensitivities to process, how shall archaeological documentation and analysis proceed? Current practice emphasizes reliably tallying quantities of things (sherds and so forth) because these somehow (and these linkages are not often specified) tell us about numbers of people (relatively or absolutely). But, the synchronic premise that undergirds such practice conflicts directly with the multi-temporal understanding of palimpsest deposits articulated above.

In light of this understanding of the unique information capacity of archaeological elements, three kinds of inferential tools have been used by archaeologists. The first and most common, point indicators, rely on the presence/absence of particular material remains to inform on particular possible conditions. The presence of an African Red Slip sherd in interior Rough Cilicia indicates some kind of relationship with the greater Mediterranean market. An assembly house at Asar Tepe (Rough Cilicia), for example, signifies that at least at one point in time, the multifarious conditions supporting the creation of an assembly hall existed. Similarly, the presence of baths and fortification walls signal that yet other conditions are in place at some restricted point in time. Point indicators are typically used comparatively-on which hilltops are fortified cities found-or, populations of point indicators-numbers of African Red Slip sherds-are also informative.

Span indicators, on the other hand, refer to assemblages of artifacts or features that accumulate over a particular span of time. An assemblage of pristine features would suggest a very short occupation span; an assemblage of features showing repeated modification would suggest a rather longer or more intense occupation span. An assemblage composed only of domestic ware sherds, again, reflects a brief domestic occupation; an assemblage also containing storage sherds suggests longer domestic occupation. The relative ratios of material culture with different life spans offer another way to understand the prevailing conditions over the long term. A number of Prehistoric archaeologists (Bamforth and Becker 2000; Binford 1977; Holdaway et al. 2004) have explored the utility of span indicators derived from time-averaged (Stern 1994) chipped stone assemblages. The same needs to be attempted for assemblages from more complex societies. 
The material histories of artifacts, features, and surfaces are one last source of inferential power. Small, battered artifacts suggest they have spent some time in the plow zone (Wilkinson 1982); pristine sherds may reflect recent looting activity. Features with little modification vs. those enhanced through repeated building events vs. those showing deliberate destruction suggest different longerterm roles of those features in the cultural landscape (Chapman 1994; 1999). Finally, the work of Van Andel and colleagues (Van Andel and Runnels 1987; Van Andel et al. 1997; Van Andel et al. 1995; Van Andel and Zangger 1990; Van Andel et al. 1990) has demonstrated how surface and landscape history can inform on the configuration of the human-natural landscape.

Point indicators, span indicators, and material histories, of course, are not unproblematic inferential tools. The middle-range research required for them to perform meaningfully is not to be denied and remains on the horizon.

\section{Conclusion}

Archaeological landscape studies in the Mediterranean are at a critical crossroads. Because of the intensity and great technical sophistication with which archaeological survey has been done here, we increasingly appreciate that we deal with a formationally complex landscape that potentially informs on more than the historicist time dimension emphasized by most settlement pattem surveys. How are these other interesting temporalities to be approached? Here 1 have identified two methodological needs: one is a more complete library of potential short-, medium-, and long-term processes at work in creating the archaeological landscape; the second consists of inferential tools based in the material histories of artifacts, assemblages, features, and surfaces. With these various conceptual and methodological tools in place, the potential of the rich archaeological landscapes of the Mediterranean to better complement the equally rich textual record is boundless.

\section{Acknowledgments}

I thank my Rough Cilician compatriots-Nicholas Rauh, Matt Dillon, Michael Hoff, and Rhys Townsend - for their insights. Thanks also to Effie Athanassopoulos and other symposium participants for stimulating discussions on Mediterranean archaeological landscapes and to Simon Holdaway for introducing me to the term "time perspectivism." Errors in thought remain my own.

This chapter is one in a series of reports that explore aspects of time perspectivism in archaeological deposits from the Mediterranean and elsewhere. A followon paper to this chapter was presented in the Side-by-Side Conference, hosted by Susan Alcock and John Cherry at the University of Michigan (Ann Arbor) in spring 2002 (see Wandsnider 2004). 